\section{Fretting about the future}

\section{Munlch}

RECEIVING an offer to become director of a Max Planck Institute is still the dream of many researchers in and out of West Germany, and no wonder: no teaching responsibilities, a lifetime position and the opportunity to do research without having to apply for grants are among the privileges a director enjoys. But members of the Max Planck Society (MPS) have become concerned that the high scientific standards of the illustrious society might start to slip.

The MPS scientific council sounded an alarm earlier this summer with a two-day symposium on "Generational dynamics and innovation in basic science". The symposium did more to identify disturbing questions concerning the future of MPS than to answer them.

On the one hand, the lower ranks of MPS are filling up with people who have lifetime tenure. But in the next few years, MPS will have to appoint dozens of new directors to replace those who will be retiring. MPS is now asking itself if its current structure is worth maintaining.

MPS has achieved its status in part because of its unusual structure. Because a director with a lifetime appointment is not required to publish, he or she can choose a project that takes many years or that requires special training. That allows for the type of project that led to the 1988 Nobel prize in medicine or physiology (awarded to Hartmut Michel, Robert Huber and Johann Deisenhofer who did the work at the MPS Institute for Biochemistry) - an interdisciplinary project that takes several years and calls for researchers with highly specialized capabilities.

As an indicator of its success, MPS has lured numerous German researchers back home from good overseas posts; Stanford University and the biotechnology company Genentech have recently lost senior people to MPS.

The principle upon which the predecessor of MPS, the Kaiser Wilhelm Society (KWS), was founded in 1911 still affects life in MPS today. The 'Harnack principle', named after Adolf von Harnack, a theologian and a founder of KWS, called for a scientific institute to be built around a leading personality in science, where the person could be surrounded by subordinates of his or her choosing.

The principle has admittedly been tempered in MPS (which was set up in 1948) by the practice of having several directors in a single institute. In many cases, an institute has department heads who form an executive board that makes decisions on a majority basis. But the biochemistry institute in Martinsried is more typical. There, each of the 11 directors has his own budget, with autonomy over decisions on personnel and laboratory space. The director is thus an absolute monarch within his own department.

It is this freedom that makes an MPS directorship such a dream - but von Harnack certainly never reckoned with the impact of West German labour law on scientific flexibility. When a director retires from a Max Planck Institute, it can in theory be shut down and its resources given to a new director in a different field. In practice, however, each director leaves large groups of employees behind.

These people, as qualified as they might be, can be a millstone around the neck of the director's successor, if his or her research takes a new tack. Under West German law, these employees may not be made redundant.

The next director is required to find work for them until they retire, which can often take ten to twenty years. When the present MPS president Heinz Staab took office in 1984, roughly 75 per cent of MPS scientific personnel had lifetime positions. Staab considered this a handicap for MPS in its search for the best new directors and he urged that more people

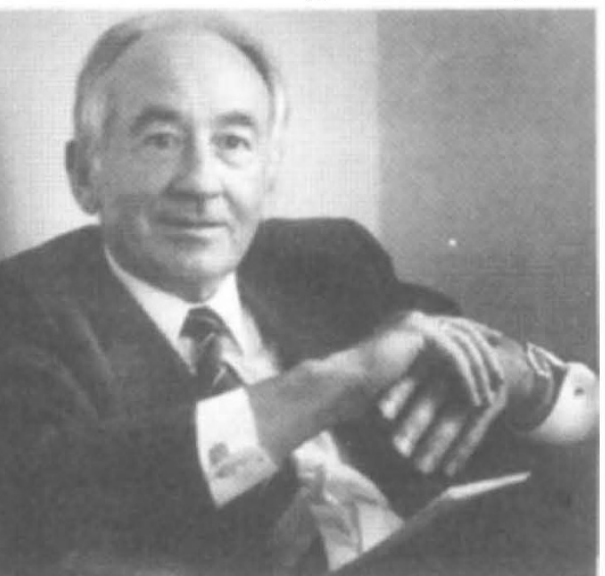

Staab of MPS: Sees little prospect of reducing the number fifetime tenure posts.

be hired on short-term contracts. But in five years, the number of staff with lifetime positions has fallen little and Staab says he does not see how it could be reduced much more in the foreseeable future.

Many of the recent problems in MPS can be traced to the sclerosis that has gripped West German universities in the 1980s. Formerly, even subordinate researchers with lifetime positions could be counted on to leave MPS for a university job when the right offer came along. Now, there is a jam at the top of the steep pyramid that is a West German university, so these offers come rarely. By contrast, a
US university faculty is structured "more like an inverted pyramid, with most positions at the highest level", said Harvard sociologist Aage Sorensen at the symposium.

Sociologist Hans Joas of the University of Erlangen pointed out that West German universities need a more complete career ladder, complete with middle rungs. Otherwise, the boom-or-bust cycle for young researchers that began in the generous university expansion of the 1960 s will continue. Research administrators all over West Germany are asking themselves how to break this cycle. For MPS, some think the large turnover at the top will be good - it "will only increase the scientific standard", says Ken Holmes, an MPS director in Heidelberg. But efforts to bring in and hold onto the best people will have to be redoubled when the logjam at universities breaks.

Otherwise, says another director, these same people may jump at university jobs, leaving behind the 'dead wood'. In the opinion of Jeff Schatz, a biologist at the University of Basel who has served on two MPS advisory boards, MPS has made one of its best contributions to West German science by establishing small institutes such as the Friedrich Miescher Laboratory in Tübingen.

The great advantage of the Miescher laboratory is its policy of "five years and out", which Staab says is enforced flexibly but firmly to keep up the flow of new people. In the coming years, said Staab, new laboratories will be installed exclusively for junior researchers in biologyrelated institutes in Cologne, Berlin, Freiburg and Martinsried. But the number of young people thus employed will be only a tiny fraction of the overall MPS payroll of 2,400 scientific positions.

Despite the symposium, radical change within MPS seems unlikely. Once a director is appointed, he or she usually does not push very hard to change the system that is supporting him so generously. One person who did try to change things, Nobel laureate Georges Köhler of Freiburg, learned quickly that the MPS administration has a strong interest in defending the status quo. Köhler, who has been at MPS for five years, suggested that middle-level positions be created and that young researchers be offered the opportunity to stay at MPS. His suggestion fell on deaf ears. "It is my impression that the administration wanted to maintain the current system because it is easier to administer", he says.

But Staab is stepping down next year, and the selection of a new president may bring about a reassessment. Trying to shake a society burdened by its own custom and by external conditions will not be easy; but the next president, who will be in office until 1996, may by then have no choice.

Steven Dickman 